STUDIA IBERYSTYCZNE

18 (2019), pp. 467-478

https://doi.org/10.12797/SI.18.2019.18.32

Galina Petrova

Universidade Estatal de Relações Internacionais de Moscovo galia.petrova@mail.ru

\title{
Conceitos do tempo e do espaço em russo e em português: diferenças e dificuldades na aprendizagem
}

\begin{abstract}
Resumo:
$\mathrm{O}$ artigo analisa as diferenças estruturais entre as línguas russa e portuguesa no domínio dos conceitos do tempo e do espaço e os erros típicos dos alunos russofalantes provocados por estas distinções. Elas são as seguintes: o calendário russo começa a semana com a segunda-feira, enquanto no caso do português, com o domingo; as 24 horas do dia são divididas e denominadas em russo e em português de maneira diferente. Enquanto o português descreve a posição do objeto no espaço mediante os verbos genéricos, o russo especifica a sua posição horizontal ou vertical. Os conceitos espaciais e temporais na língua portuguesa podem expressar-se pelos mesmos lexemas, ao passo que em russo esta confusão é praticamente impossível.
\end{abstract}

Palavras-chave: tempo e espaço, ensino de língua portuguesa; erros dos russofalantes, análise comparativa, diferenças lexicais

\section{Abstract:}

The Concept of Time and Space in Russian and Portuguese: Differences and Difficulties in Learning

The article analyzes main structural differences between the Portuguese and Russian languages in the field of concepts of time and space and typical mistakes Russian-speaking students make as a result of these distinctions. Those are: days of the week and times of the day are expressed in a different fashion; while 
Portuguese describes the object's position with generic verbs, Russian specifies its horizontal or vertical position. In Portuguese both space and time-related concepts are expressed with the same lexemes while in Russian it is impossible.

Keywords: time and space, teaching Portuguese, Russian speakers' mistakes, comparative analysis, lexical differences

\section{Introdução}

Este trabalho é dedicado às dificuldades dos alunos russofalantes no processo de aprendizagem do português, visando analisar as diferenças lexicais relativas à representação do tempo e do espaço nas duas línguas. Estas diferenças, refletidas na língua, provocam erros que representam uma espécie de "sotaque russo" e são próprios de quase todos os russofalantes. $\mathrm{O}$ trabalho sintetiza a experiência prática da autora ao longo de 40 anos de ensino do português a alunos universitários dos níveis A1-C1, cujo número total excede os 900 . A análise abaixo pode eliminar erros frequentes e contribuir para a metodologia do ensino da língua portuguesa a russofalantes e, em alguns casos, a falantes de outras línguas eslavas.

Os exemplos literários e da imprensa periódica são tirados dos corpora (Corpus do português) e (Now Corpus: Portuguese).

É notório que vemos o mundo sob o prisma da nossa língua materna que impõe uma impressão indelével sobre a nossa mentalidade. Wilhelm von Humboldt destacou que "a língua reflete as caraterísticas que são externas ao indivíduo e que interferem no seu comportamento e nas suas sensações individuais. A língua é a imagem do espírito nacional: ela reflete tudo o que está na alma dos indivíduos de uma nас̧ão". (Гумбольдт, 1985: 370).

Dando seguimento a este conceito, Anna Wierzbicka investigou a compreensão das culturas através de palavras-chave (Вежбицкая, 2001). No material da língua russa, o seu trabalho foi prosseguido, em particular, pelos linguistas Anna A. Zalizniak, Irina B. Levóntina e Aleksey D. Schmeliov (Zalizniak [et al.], 2005). 


\section{Tempo}

2.1. Dias da semana. Entre as línguas românicas, o português foi o único que aceitou a denominação dos dias da semana segundo o Antigo Testamento, em que todos os dias da semana, exceto o sábado (o shabbath), são chamados de primeiro, segundo, terceiro etc. dias da Criação (Gênesis 1-2). As outras línguas românicas usam nomes romanos, provindos das designações de deuses romanos e respetivos planetas (Lunae dies, Martis dies, Mercurii dies, Jovis dies, Veneris dies, Saturni dies e Solis dies).

Na denominação do sábado, as línguas românicas e eslavas herdaram a tradição hebraica, aceitando a palavra shabbath, enquanto no nome do domingo prevaleceu a tradição cristã: o nome pagão «Dies Solis», dia do Sol, foi substituído por "dies domenicus" (dia do Senhor).

O bispo de Braga e de Dume, Martinho de Dume (cerca de 510580), considerando indigno de bons cristãos que se continuasse a chamar os dias da semana pelos nomes pagãos, "dar nomes de demónios aos dias que Deus criou", foi o primeiro a usar a terminologia eclesiástica para os designar (Feria secunda, Feria tertia, Feria quarta, Feria quinta, Feria sexta, Sabbatum, Dominica Dies (Fletcher, 1999: 257).

A língua portuguesa, no entanto, herdou a tradição hebraica, na qual o domingo é o primeiro dia depois do shabbath, a segunda é o segundo dia etc. Assim, entre as línguas novilatinas, o português foi a única língua a substituir inteiramente a terminologia pagã pela terminologia bíblica.

O Imperador Constantino o Grande, a 7 de março de 321, fez do domingo um dia de descanso (Kenneth, 2005: 68), e esta tradição cristã foi adotada pelo russo: a contagem dos dias começa a partir da segunda-feira. "Воскресенье" (o domingo) que se traduz como ressurreição, é o último dia da semana. Assim, temos o quadro seguinte: 


\begin{tabular}{|c|c|}
\hline português & russo \\
\hline domingo & воскресенье (ressurreição) \\
\hline segunda-feira (segundo dia) & $\begin{array}{c}\text { понедельник (dia depois do dia em que } \\
\text { па̃o se faz nada - неделя) }\end{array}$ \\
\hline terça-feira (terceiro dia) & вторник (segundo dia) \\
\hline quarta-feira (quarto dia) & среда (dia em meio da semana) \\
\hline quinta-feira (quinto dia) & четверг (quarto dia) \\
\hline sexta-feira (sexto dia) & пятница (quinto dia) \\
\hline sábado & суббота (sábado) \\
\hline
\end{tabular}

Não é por acaso que na designação dos dias da semana os russofalantes, conforme a mentalidade que lhes é própria, se enganam frequentemente: (segunda-feira é "вторник", segundo dia da semana na tradição russa, terça é “среда", terceiro dia, etc., o que dá motivo para vários mal-entendidos e desencontros).

2.2. Períodos do dia. As palavras que significam em português e em russo os períodos do dia não coincidem. Em português não há uma palavra para designar o lapso de 24 horas, incluindo dia e noite, o que é "сутки" (24 horas) em russo. Os russofalantes sentem dificuldade em traduzir: "Я не спал трое суток". - Não dormi três dias e três noites? Ou não dormi 72 horas?

Para os principiantes as dificuldades começam logo, nos cumprimentos. Sendo que o dia é um período claro, e a noite, escuro, os portugueses não cumprimentam na parte matutina os seus próximos com Boa manhã!, mas dizem Bom dia! Quando dizem Boa tarde!, na verdade não é tarde, estão em pleno dia. E a noite começa às seis da tarde e dura 12 horas, sem ser dividida num período em que as pessoas estão acordadas (fr. le soir) e período em que estão a dormir (fr. la nuit). A partir da meia-noite, começa a madrugada, termo usado a par da noite (são duas da noite ou duas da madrugada, ou, ainda mais paradoxal, duas da manhã), mas é um período mais escuro e distante do nascer do sol. 
Os russos dizem de manhã “доброе утро!” (boa manhã), de dia, “добрый день”! (bom dia), à noite, “добрый вечер!” (bonsoir) е “доброй ночи!” (boa noite). Não é por acaso que os aprendentes fazem erros, ao traduzir Ontem à noite como "Вчера ночью", е Hoje à tarde como "Сегодня вечером".

Os russo- e lusofalantes dividem o dia em quatro partes, mas estas partes são diferentes. Em russo são manhã-dia-soir-noite, em português: manhã-tarde-noite (-madrugada).

\begin{tabular}{|c|c|}
\hline português & russo \\
\hline \multicolumn{2}{|c|}{ Período do dia } \\
\hline 01h00-12h00: a manhã & $6 \mathrm{~h} 00-12 \mathrm{~h} 00$ утро \\
\hline 6h00-18h00: o dia & $12 \mathrm{~h} 00-18 \mathrm{~h} 00$ день \\
\hline 12h00-18h00: a tarde & $18 \mathrm{~h} 00-22 \mathrm{~h} 00$ вечер \\
\hline 18h00-6h00: a noite & $22 \mathrm{~h} 00-6 \mathrm{~h} 00$ ночь \\
\hline 12h00-6h00: a madrugada &
\end{tabular}

\begin{tabular}{|c|c|}
\hline \multicolumn{2}{|c|}{ Cumprimentos } \\
\hline 6h00-12h00: bom dia! & $6 \mathrm{~h} 00-12 \mathrm{~h} 00$ доброе утро! \\
\hline 12h00-18h00: boa tarde! & $12 \mathrm{~h} 00-18 \mathrm{~h} 00$ добрый день! \\
\hline 18h00-6h00: boa noite! & $18 \mathrm{~h} 00-22 \mathrm{~h} 00$ добрый вечер \\
& $22 \mathrm{~h} 00-6 \mathrm{~h} 00$ доброй ночи! \\
\hline
\end{tabular}

Nas locuções daqui a oito (quinze) dias uma semana conta oito dias, e duas semanas, respetivamente, quinze, incluindo o dia de hoje. $\mathrm{O}$ russo e as línguas eslavas começam a contagem a partir do dia seguinte e dizem: “через неделю”, “через две недели”, isto é, daqui a uma semana (sete dias), daqui a duas semanas (catorze dias): Tu daqui a quinze dias vens? - Talvez... (Queirós: Primo). - Ты приедешь через две недели? Os aprendentes costumam traduzir erroneamente daqui a oito / quinze dias como "через восемь / пятнадцать дней" (daqui a oito / quinze dias). 


\section{Espaço: eixo vertical ou horizontal}

Estamos orientados no espaço de maneira diferente. Em russo a deslocação costuma ser horizontal: dizemos "seguir (ir) pela rua", enquanto os portugueses nunca hesitam em determinar se descem ou sobem a rua, mesmo que seja plana: (1) Era de novo Fevereiro, um fim de tarde arrepiado e cinzento, quando eu desci os Campos Elísios em demanda do 202 (Queirós: A Cidade e as Serras). (2) Eu saía para ir almoçar e vinham aquelas multidões a subir a Rua Garrett e a Rua do Carmo (Observador).

Analisando as diferenças da mentalidade russa, é de notar que o centro da cidade na representação de um russo- ou um francofalante está situado no ponto mais alto, na montanha ou colina, enquanto o centro nas cidades portuguesas, regra geral, está situado em baixo, ao pé do rio, e se chama Baixa (cf. a tradição anglo-saxónica, ingl. downtown).

As coordenadas geográficas estão também ligadas ao eixo vertical: ir lá para cima em Portugal significa ir para norte, enquanto ir lá para baixo quer dizer ir para sul. Este facto, possivelmente, é determinado pela orientação geográfica de Portugal, estendido verticalmente do norte para o sul.

3.2. As línguas românicas, regra geral, não especificam a posição vertical ou horizontal do objeto inanimado, optando pelo verbo genérico. Em português nestes casos usam-se os verbos pôr, colocar, meter ou botar que só se distinguem estilisticamente. O russo explicita obrigatoriamente os eixos horizontais e verticais, utilizando "класть" (colocar alguma coisa deitada), “ставить" (colocar de pé), е “вешать" (pendurar), o que é próprio também do alemão e do holandês (Rachilina, Lemmens, 2003). Cf: (3) Achei um saco de pão, peguei duas fatias е coloquei no forno elétrico (Terra). - Я нашел пакет с хлебом, взял два ломтика и положил (coloquei deitadas) в духовку. (4) O contrato foi revisado e eu coloquei a assinatura final (Istoe). - Контракт был пересмотрен, и я поставил (coloquei de pé) свою подпись. (5) Аpaguei a luz do meu ponto, coloquei as roupas mais para perto (Exame. com). - Я погасила свет в магазине и повесила (pendurei) одежду 
поближе. A expressão fraseológica estar por um fio tem um análogo russo "висеть на ниточке" (estar pendurado por um fio).

As locuções de pé e deitado usam-se em português só quando a posição vertical ou horizontal do objeto é relevante: (6) Se você deitar o aparelho por algum motivo, é bom manter estável e de pé por duas horas antes de religar (emcasasozinho.wordpress.com).

Da mesma maneira, na descrição de uma posição fixa e duradoura de um objeto animado, enquanto o português na maioria dos casos dispensa a especificação da sua posição, em russo os verbos "стоять" (estar de pé), “сидеть” (estar sentado), е “лежать” (estar deitado) são obrigatórios: (6) Eu só me coloquei no lugar dele (BeSoccer P) Я просто поставил (coloquei-me de ре́) себя на его место. (7) - Que suspiros são esses, D. Ângela? perguntou o Dr. Silveira, que estava ao seu lado (Azevedo: Casa de Pensão). - Что за вздохи, Дона Анжела? - спросил доктор Силва, который стоял (estava de pé) с ней рядом. A posição do objeto em português é determinada só pelo contexto: (8) Esquecera-se do tempo, das aulas, de mim próprio, que estava ao seu lado... (Costa Sousa: Excêntricos). - Она забыла обо времени, о занятиях, даже обо мне, который ?стоял/сидел/лежал (?estava de pé/sentado/deitado) рядом.

O análogo russo da expressão ficar no hospital - “лежать в больнице" (estar deitado no hospital) - põe em relevo a posição horizontal do doente; estar na prisão - “сидеть в тюрьме" (еstar sentado na prisão) - a posição sentada de um preso; ficar em casa é “сидеть дома" (estar sentado em casa); ficar de braços cruzados é “сидеть сложа руки” (estar sentado de braços cruzados); ficar sem dinheiro é "сидеть без денег” (estar sentado sem dinheiro). Os russofalantes recorrem muitas vezes à tradução literal, introduzindo as locuções expletivas: "Estava sentado de braços cruzados à sua espera".

\section{Direção do movimento}

Falando do eixo vertical ou horizontal, não podemos deixar de observar que nas línguas românicas os passageiros podem subir nos meios de transporte ou descer deles, enquanto em russo eles só entram neles 
ou saem deles: (9) Gil desceu do ônibus e começou a subir a rua, na direção de casa (Veríssimo: O Resto é Silêncio).

A empatia do observador, a sua posição diferente nas duas línguas provoca outras distinções: enquanto para os lusofalantes os atores entram no palco e os futebolistas entram no campo, em russo diz-se: “Актеры выходят на сцену” (saem ao palco), “Футболисты выходят на поле" (saem ao campo): (10) Nós só podíamos entrar no campo às 11 (Intrv: ISP). - Мы могли выйти на поле только в 11. (11) Ricardina entrou no palco com os outros candidatos (Gattai: Crônica). - Рикардина вышла на сцену с другими кандидатами. É natural que nas traduções para português se encontrem erros, determinados pelo impacto da língua materna (sair ao palco, ao campo).

\section{Tanto o tempo como o espaço}

Em português os mesmos lexemas expressam noções tanto espaciais como temporais. O mundo é visto como que um contínuo espácio-

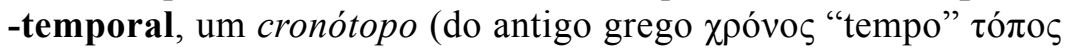
"lugar"), conceito apresentado por M. M. Bakhtin (1990), em que o tempo e o espaço são inseparáveis e se confundem, e isso reflete-se na língua. "Profundamente relacionadas com as perceções sobre o espaço, estão as do tempo, fazendo, as duas, microssistemas frequentemente intercambiáveis e intermutáveis na referenciação linguística dos aspetos que as envolvem, ou seja, dos aspetos relativos às dimensões espácio-temporais" (Teixeira, 2013: 57). Nas designações do tempo encontram-se as mesmas locuções que marcam a deslocação no espaço, por ex.: fumando cigarro atrás de cigarro (Teixeira, ibid. 63), ao longo do tempo e outros. Cf.: (12) Nesse momento Carlos arremetia pela sala dentro arrastando a sua noiva, a Teresinha (Queirós: Os Maias). (significado espacial) vs (13) Tudo indicava que a festa (...) se iria prolongar pela madrugada dentro (Observador) (significado temporal).

Em português, os pontos de referência aqui e agora coincidem e estão interligados, e nas expressões temporais usam-se advérbios de lugar: daqui (dai, dali) a algum tempo: (14) Não sabemos o que vai 
acontecer amanhã ou daqui a uma hora (pleno.news). Na língua russa, os exemplos de cronótopos são poucos: "промежуток времени" (um espaço de teтpo), “с течением времени” (com o decorrer do tempo) e a expressão metafórica "река времени” ( o rio do tempo). No entanto, na maioria dos casos o russo costuma separar as noções de tempo e de espaço e, segundo as minhas observações, os russofalantes evitam expressões do tipo daqui a uma hora, preferindo dentro de uma hora.

Por sua vez, nas expressões do tipo: dentro de uma hora e a partir daquele momento o tempo é representado metaforicamente como um espaço em que se pode mergulhar, uma matéria que tem superfície, profundidade ou um ponto físico de partida. Em russo encontramos tal emprego apenas no uso da preposição “через" no sentido tanto espacial como temporal: "через час" (dentro de uma hora) и "через лес" (através da floresta).

\section{Verbos de movimento}

Falando de diferenças estruturais, não se pode deixar de abordar o tema dos verbos de movimento. Este tema parece ter sido esgotado por Vladimir Gak (Гак, 2013) e pelos seus numerosos sucessores. No entanto, ele não deixa de ser complicado para os aprendentes.

A língua portuguesa, como outras línguas românicas, é centrada no sujeito de enunciação: o espaço nela está organizado em torno do falante. Os verbos de movimento usam-se conforme a posição do falante: para designar o movimento em direção ao falante, empregam-se os verbos trazer; vir; puxar. A direção inversa, o afastamento do falante, é descrita pelos verbos ir; levar; empurrar. No exemplo seguinte, vir é possível só se o falante está no Brasil: (15) - Por que a companhia vem ao Brasil? (Caroline).

Mas se a deslocação se realiza do ponto aqui ao ponto ali, mas juntamente com o falante, o ponto aqui desloca-se com o falante. Nestes contextos, emprega-se o verbo vir em vez de ir: (16) Há muita gente à tua espera, vem comigo (Público). O russo, sendo uma língua sintética, consegue juntar numa forma verbal vários semas, transmitindo, por meio do prefixo, o significado da direção do movimento: “приходить”, 
“выходить”, “уходить” (vir, sair, ir-se embora) e, na raiz, o do modo de deslocação: “приходить”, “приезжать”, “приползать”, “прилетать” (vir a pé, no transporte, arrastando-se, voando), mas nunca a posição do falante em relação ao interlocutor. Daí, os erros mais frequentes cometidos pelos russofalantes são: *Leva-me o meu casaco. *Vai comigo! O Mário vai hoje a minha casa.

\section{Conclusão}

Como podemos verificar, o russo e o português dividem de maneira diferente o tempo e o espaço, o que representa algumas dificuldades para os principiantes. A contagem dos dias da semana não coincide: o calendário russo começa a semana com a segunda-feira, enquanto o português, com o domingo; as 24 horas do dia são divididas e denominadas de maneira diferente; o português descreve a posição do objeto no espaço mediante os verbos genéricos, enquanto o russo especifica obrigatoriamente a sua posição horizontal ou vertical. Os conceitos espaciais e temporais na língua portuguesa podem expressar-se pelos mesmos lexemas, enquanto em russo esta confusão é praticamente impossível.

\section{Referências bibliográficas}

BACHTIN, M. M. (1990), "Forms of Time and of the Chronotope in the Novel: Notes toward a Historical Poetics" em: Holquist, M. (ed.), The Dialogic Imagination: Four Essays, University of Texas Press, Austin, pp. 84-258.

CORPUS DO PORTUGUÊS [on-line] http://www.corpusdoportugues.org/ -5.03 .2019 .

FLETCHER, R. A. (1999), The Barbarian Conversion: From Paganism to Christianity, University of California Press, Berkeley.

KENNETH, A. S. (2005), "Como o domingo tornou-se o popular dia de Culto - parte 2", Parousia - $1^{\circ}$ semestre, São Paulo [on-line] http://www.centrowhite.org.br/pesquisa/artigos/como-o-domingo-tornou-se-o-popular-dia-de-culto-parte-2 - 30.12.2018. 
NOW CORPUS: PORTUGUESE [on-line] https://www.corpusdoportugues. org/now/- 5.03.2019.

RACHILINA, E. V., LEMMENS, M. (2003), "Russian and Typological Linguistics: The Lexical Semantics of Verbs with the Meaning Sit in Russian and Dutch", Russian Linguistics, 27(3), pp. 313-327, https://doi. org/10.1023/A:1027325127170.

TEIXEIRA, J. (2013), "Sinonímia e processos de implicação: algumas relações entre espaço e tempo no Português Europeu”, Древняя и Новая Романия, вып. 11, pp. 56-77 [on-line] https://repositorium.sdum.uminho. pt/bitstream/1822/27469/1/EspacTempTEXTO\%20FINALnoLivro.pdf -22.03 .2019 .

ВЕЖБИЦКАЯ, А. (2001), Понимание культур через посредство ключевых слов, Языки славянской культуры, М.

ГАК, В.Г. (2013), Сравнительная типология франиузского и русского языков, Либроком, М.

ГУМБОЛЬДТ, В. (1985), Язык и философия культуры, Прогресс, М.

ЗАЛИЗНЯК, А.А. ЛЕВОНТИНА, И.Б., ШМЕЛЕВ, А.Д. (2005), Ключевые идеи русской языковой картины мира. Сборник статей, Языки славянской культуры, М.

ПЕТРОВА, Г.В. (2016), “Окружающая реальность через призму русского и португальского языка. Понятия времени и пространства”, Риторика. Лингвистика, 12, Смоленск, pp. 324-334. 